\title{
Understanding the Challenges of Blockchain Technology Adoption: Evidence from China's Developing Carbon Markets
}

\author{
Xing Chen \\ Business School, \\ The University of Edinburgh \\ xing.chen@ed.ac.uk
}

\author{
Ashley D. Lloyd \\ Business School, \\ The University of Edinburgh \\ ashley@edinburgh.ac.uk
}

\begin{abstract}
Blockchain technology promises disruptive change to industry and society. Although academic researchers and practitioners have engaged with blockchain for years, actual adoption rates of this technology significantly lag predictions. This paper explores present barriers to blockchain adoption in an industry for which blockchain might be assumed to offer an obvious solution to a globally distributed challenge: the integration of carbon markets. Using technological framing theory as a focusing lens, we investigate the challenges of blockchain adoption in China's developing carbon markets from three expert groups: carbon market experts with blockchain knowledge only, carbon market experts with blockchain projects, and IT experts in carbon markets. Our findings suggest that different expert groups present distinctive and incongruent framing challenges where technical challenges are not the most significant. In exploring this we make contributions to the introduction of a socio-technical perspective in blockchain adoption research and provide practical suggestions to policymakers and practitioners.
\end{abstract}

\section{Introduction}

Blockchains are open, append-only, distributed networks that are regulated through a peer consensus mechanism and secured with cryptography [1][2]. Blockchain promises to revolutionize industries and redefine basic structures in economic, legal, and political systems [3]. This potential is characterized by five fundamental principles: decentralization, data immutability, transparency, strict verification, and privacy and security [4][5]. In the most primordial blockchain system, transaction records are continuously inscribed onto a ledger within a certain time and packed together onto a "block". Through a hashing function, each block creates an irreversible cryptographic link to its previous block together with identical timestamps and data of all transactions recorded on this unit. This linking action, as well as verification, proceeds through shared governance protocols across all participating nodes within the network. After linking, each node will contain a complete record of all the transactions in that blockchain. When blocks are chained as a growing list, they become virtually immutable and resist deletion, tampering, and revision from any single actor.

To launch a retroactive alteration on "chained" transactional data, the network majority must run cryptographic algorithms to assess and verify the features of the proposed individual block. A consensus must be obtained among the majority to change all subsequent blocks [6]. Such resilience to data manipulation enables blockchain to displace traditional trust-based intermediaries and to effectively secure the data in blockchain ledgers against unauthorized access and manipulation. This process also provides credibility for users to conduct a holistic audit trail of activities [7]. Further, blockchain can be enhanced with the addition of smart contracts that refer to a predefined computerized protocol to enable automatic enforcement of the relevant transactions once negotiated conditions are met [8]. This serves as a digital representation of governance rules and verification guidelines for managing digital assets.

Blockchain can be designed as either a permissionless or permissioned governance structure. For a permissioned blockchain, participants must gain authorized access before joining to set up network nodes. Such access is controlled by a consortium or by a central organization and assessed through predefined compliance criteria [6]. Permissionless blockchains however, allow users to remain anonymous in setting up nodes. For example, Bitcoin adopts a permissionless structure where there is no entry barrier to participation. Such a network has free access for its participants to all transaction records.

Given such clearly stated technical strengths and a match with global movements towards cooperative, decentralized decision-making processes 
supported by more widely distributed shared infrastructure, it may appear surprising that adoption of blockchain has lagged predictions [9][10]. To explore this for a global cooperative movement where assets need to be registered and exchanged to better address a common goal, we ask: what are the perceived challenges of blockchain adoption in carbon markets?

\section{Blockchain and carbon markets}

A blockchain research community started to emerge in 2013 and has shown rapid growth since 2016 [11][12]. Early research focused on cryptocurrencies such as Bitcoin and development of their protocols, design details of the peer-to-peer transaction network or characterization of the ecosystem [13][14][15][16][17]. These discussions set the tone of blockchain perceptions in related application areas and the direction of research development with more than $80 \%$ of studies emphasizing technical perspectives of blockchain and cryptocurrency systems and less than $20 \%$ dealing with blockchain adoption and implementation [16].

Within these we focus on studies that investigate socio-technical aspects and implications of blockchain adoption for the individual, organization, and society [5][17][18]. We find that adoption challenges from business and societal perspectives have received little attention [19] yet are critical when blockchain's capacity for radical innovation is through concurrent introduction of new management models and organizational practices [5].

In terms of an application focus, we also find that depth in blockchain application research has been narrowly focussed on finance and the supply chain. In the arena of carbon markets there are influential whitepapers and working papers that have shaped the discussion of blockchain application [20][21][22][23], yet the scholarly literature exploring blockchain application in this context remains superficial.

Carbon markets mainly involve trading services, recorded as a certain amount of carbon credits and offsets. Every single carbon credit or offset represents the service of preventing one metric tonne of carbon dioxide equivalent (CO2-e) from entering the atmosphere. However, the process of monitoring, reporting, and verifying (MRV) the carbon amounts is complicated and vulnerable to freeriding [24]. While many organizations and experts have acknowledged the potential benefits and transformational nature of blockchain technology for climate actions, no largescale deployment of blockchain solutions in carbon markets has been delivered. To date, there are numerous organizational reports (such as UNFCCC and World Bank), research initiatives, and business proposals (white papers) highlighting potentials for the carbon industry, whilst those published in academic journals work split their focus on using blockchain to either create a new carbon market or update existing schemes [25]. Drawing broadly on the above literature, blockchain is recognised to offer carbon markets distinctive strengths from the following two aspects.

\subsection{Technical Strengths}

2.1.1. Transparency, immutability and trust. Blockchain delivers a tamper-proof transaction ledger that boosts market confidence and avoids transaction disavowal [4]. This ledger comes with transparency that increases the accountability of carbon mitigation efforts and maintains information credibility [26].

A blockchain ledger for carbon trading can synthesize and support the transaction of all kinds of mitigation-related data (e.g., facility level, projects, quantified production, and life cycle attributes) in a shared, globally accessible environment [22]. This ledger system can avoid carbon leakage by allowing participants to trace and audit the end-to-end process. Blockchain raises the cost of conducting fraud of data, and tax evasion scams and boosts trust and confidence in the carbon market mechanism.

The behavioural impacts of this could be profound. With all information under scrutiny, market participants are forced to behave in a responsible and accountable manner in collecting and recording data. Monitoring and verifying the source and ownership of carbon credits helps protect the trading from fraud and other problems such as double accounting [27][28].

The enhanced transparency also increases the carbon market's efficiency by tackling asymmetric information at the transaction level. The current secondary market suffers from low liquidity and unstable prices [29]. Poor information sharing on carbon credit unit holdings and trading has distorted investment and price signals, such that one can know little about the reputation of its counterparties and the quality of their carbon unit credits [25]. Once the process of carbon credits issuance is trackable and information is more credible, potential purchasers will have more confidence in the credit's quality and participate in the carbon markets more actively.

2.1.2. Peer-to-peer efficiency and effectiveness. Blockchain-empowered carbon markets can increase the efficiency and effectiveness because it speeds up data transfer in peer to peer (P2P) networks [18][30] and widens the geographical scope of feasible trading. Such an infrastructure can be regarded as distributed database system that allows multiple participants to make alterations in the system at the same time. This 
encourages individual participation in voluntary markets where they can save carbon emissions on a daily basis and exchange it freely with others. More importantly, blockchains enable the automated execution of smart contracts in P2P networks [31]. The automated trading platform will present price signals and information on carbon costs to consumers in an efficient way, simultaneously incentivizing them for demand response and smart management of their carbon allowance needs [32].

Blockchains can also increase the efficiency of the carbon markets by lowering transaction costs. The traditional MRV process includes complex work done 'in the field' by many people and multiple layers of data checking and reporting, representing large human resource and time investments that may have significant opportunity costs. Smart contracts allow more automation of the MRV process, reducing the investment hurdle for project proponents and the bureaucratic overhead. Smart contracts can also be used to help generate the carbon credit units automatically, making the issuance process much simpler and reducing the barrier to entry of smaller mitigation projects. Currently, it takes a regulator several weeks to evaluate a report for carbon credit unit creation, hence blockchains offer the promise of faster regulation through real-time evaluation.

Since existing carbon markets around the world are fragmented and heterogenous, networking should foster market liquidity, reduce compliance costs, promote environmental technology transfer and sustainable practices [27][33][34]. However, networking has been held back by multiple challenges: harmonization of MRV provisions [33][35], double accounting [27][36], loss of regulatory autonomy [37][38]. The emergence of blockchain provides a bottom-up solution to networking carbon markets without forcing legal and regulatory homogeneous standardization and conformance on those markets [39][23]. Jackson et al. [23] proposed a federal blockchain system to not only run different carbon markets with required function designs but also interoperate and allow data transfer between the different levels. Blockchains therefore promise support for networking global emission trading systems as well as an adoption approach that enables wider participation and engagement, enhancing the long-term effectiveness of the ETS mechanism.

\subsection{Technical Challenges}

While blockchain is believed to help transit from the centralized and linear models of carbon generation and consumption models towards decentralized, distributed and inclusive carbon trading systems, it faces challenges that need to be addressed if it is to deliver the desired environmental and social impacts. Currently, most focus has been on the recognition and resolution of technical obstacles [16][6].

2.2.1. Excessive Energy Consumption. One of the most frequently discussed challenges for blockchain applications is energy requirement. The extent of such is a design choice determined by the openness of the network (permissioned or permissionless) and the type of consensus mechanism. A permissionless blockchain network with a "Proof-of-Work" (PoW) consensus, like the Bitcoin system, would require high computational power and attendant consumption of energy. The permissioned private blockchain system, in contrast, needs less energy because only a few nodes are entitled to put the next block of transactional records into the joint network data history.

This does, however, impact security and scalability. The PoW mechanism enables all network nodes to compete to solve the mathematical formula and win the right to record. This solving process needs substantial power for repetitive trials and error exercises, making it unlikely for hackers to predict the winner and hence impossible to attack directly. One energy-efficient substitute to PoW is "Proof of Stake" (PoS) which derives from the Ethereum Blockchain and includes a voting system for choosing the validators from qualified nodes with coins staked. This type of consensus algorithm only needs a small amount of energy because the network participants do not have to search and seek appropriate hashes. Malicious attack to this algorithm requires hackers to purchase a large sum of tokens and hence quickly becomes uneconomic. For example, the Confidential Consortium (CoCo) Blockchain Framework from Microsoft is a permissioned private network that replaces the PoW mechanism with simplified consensus and reduced duplicative validation, greatly lowering the electricity consumption [40].

2.2.2. Limited Scalability. Scalability emphasizes the number of users blockchain could accommodate in a time interval and the speed with which it can validate the blocks. Permissionless blockchains normally struggle to scale up performance because of an inefficient consensus mechanism. Bitcoin, for example, has a $1 \mathrm{MB}$ block size and each block can hold around 2,000 transactions. Restricted by the validating process, it takes an average of 10 minutes to produce a block, leading to seven transactions per second. In contrast, the Visa credit card system has over 65,000 transactions processed within the same period.

As noted in relation to energy consumption above, the challenge of scalability can be mitigated within a 
permissioned blockchain system by replacing the PoW mechanism with a more effective consensus choice, realizing higher transaction volume at lower power.

2.2.3. Rubbish in, Rubbish out. Although the blockchain system can keep data immutable, it is often misunderstood that data on the "chain" are accurate and represent the 'truth'. In fact, blockchain cannot intrinsically guarantee data accuracy nor prevent any form of fraud or crime before data is moved onto the "chain". When wrong data are inscribed in a block and finally transferred to the network with other blocks, the system does not verify, but preserves originality and replicates to other nodes for storage. This drawback is described as "Rubbish in, Rubbish out".

To improve data quality in the blockchain network, the accountability of the data provider and the process of data transfer, from generation to recording, should be ensured. While the former is more feasible in a permissioned network where participants' actions can be designed to be transparent, the latter can be realized in conjunction with other technologies such as GPS, RFID, or other IoT devices, for automatic data transfer.

\subsection{Framing Challenges}

Research on IT innovation adoption and diffusion has accumulated a quite rich body of theoretical and empirical work. In this tradition, researchers tend to put more focus on the implementation phase, with less on the pre-adoption phase [7]. However, the preadoption phase plays an important role for organizations to explore a technology's features, investigate its benefits and challenges in the application domain, and determine whether or how much they will invest in it, especially when the technology is complex and potentially disruptive. Previous research on adoption has employed behavioural models, such as TRA [41], TAM [42], TPB [43], and UTAUT [44], to reveal factors that influence organizational adoption of a particular technology. Such research frames technology adoption as deterministic, yet provides limited insights into how potential adopters recognise a new technology as potentially relevant and then form assumptions, expectations, and knowledge of this innovation that shape their later actions.

In this paper, technology is framed as social artifacts with their materials and functions embodying stakeholders' knowledge, objectives, values, and interests in that technology [45]. We take a socialcognitive approach to research the pre-adoption phase and use the theoretical lens of technological framing to identify the sets of members' group frames pertaining to the assumptions, expectations, and knowledge stakeholders use to interpret technological phenomenon in a particular context [45][46][47][48] in this case blockchain in China's carbon markets.

\section{Research methodology}

Our sample focuses on experts from China's carbon markets who have an understanding of blockchain technologies and are capable of contextualizing its adoption. These include senior executives or managers who had profound domain knowledge of China's carbon markets operation and had an in-depth understanding of IT; those who are IT experts with a sufficient understanding of China's carbon markets operation; or those who are expert in both domains.

The procedure for interview preparation had three steps: first, we started with the collection of online resources (conference reports, blogs, project whitepapers) that discuss blockchain application in China's carbon markets and extracted a list of potential candidates for interview (retaining these sources for later triangulation of responses). We also considered that there might be experts in China's carbon markets who are not visible in public, yet have a deep understanding of our research topic. Therefore, we identified key senior officers at the Ministry of Ecology and Environment of the People's Republic of China responsible for ensuring attainment of national emission reduction targets and involved in governing China's carbon markets [49]; the Certification and Accreditation Administration of the People's Republic of China (CNCA) responsible for research and standardisation related to accreditation and conformity assessment (involving information system deployment standards in national carbon markets) [50]; the Alliance of Carbon Emissions Trading; the China Energy Conservation Association; and senior carbon trading managers in some enterprises such as China National Offshore Oil Corporation (CNOOC).

Holding these two name-lists, we used a personal research network established through two decades of collaborative international work involving the Chinese Academy of Science to approach experts directly, or indirectly through key industry conferences or events. Those experts meeting the selection criteria were sent an interview protocol and an interview arranged.

These two steps only identified seven carbon market experts that met the criteria. Guided by purposive sampling and data saturation [51][52], we utilized the snowballing technique [53] to ask whom else the interviewee recommended as relevant to the study. Our sampling process ceased when no new informants were being recommended, leading to a total of 15 carbon market experts (Table 1). 
Table 1. Interviewee characteristics

\begin{tabular}{|c|c|c|c|c|}
\hline Role (s) & Organizations & Groups & $\begin{array}{l}\text { Informant } \\
\text { code }\end{array}$ & Interview \\
\hline Co-Founder & $\begin{array}{l}\text { company providing blockchain solutions to carbon } \\
\text { markets }\end{array}$ & EBP & 1PT01 & Phone \\
\hline Chairman \& CEO & carbon consulting service provider & EBP & 1PT02 & Face to face \\
\hline Co-Founder \& CEO & carbon consulting service provider & EBP & 1PT03 & Face to face \\
\hline Co-Founder & carbon consulting service provider & EBP & 1PT04 & Phone \\
\hline CEO & carbon consulting service provider & EBP & 1PT05 & Phone \\
\hline Co-Founder \& CEO & $\begin{array}{l}\text { company providing blockchain solutions to carbon } \\
\text { markets }\end{array}$ & EBP & 1PT06 & Phone \\
\hline Co-Founder \& CEO & $\begin{array}{l}\text { company providing blockchain solutions to carbon } \\
\text { markets }\end{array}$ & EBP & 1PT07 & Face to Face \\
\hline Strategy Director & $\begin{array}{l}\text { company providing blockchain solutions to carbon } \\
\text { markets }\end{array}$ & EBP & 1PT07 & Face to Face \\
\hline Co-Founder \& CEO & $\begin{array}{l}\text { company providing blockchain solutions to carbon } \\
\text { markets }\end{array}$ & EBP & 1PT08 & Phone \\
\hline Deputy Director & Low carbon test and certification center & EBK & 2NP01 & Face to Face \\
\hline Secretary General & $\begin{array}{l}\text { Green Finance Association, Municipal Bureau of } \\
\text { Financial work }\end{array}$ & EBK & 2NP02 & Face to face \\
\hline Operation Director & Low Carbon Research Institute & EBK & 2NP03 & Phone \\
\hline IT leader & information system service provider in carbon markets & IT experts & ЗІT01 & Face to Face \\
\hline IT Manager & information system service provider in carbon markets & IT experts & 3ІТ02 & Face to Face \\
\hline CEO & information system service provider in carbon markets & IT experts & ЗІТ03 & Face to Face \\
\hline
\end{tabular}

\subsection{Data analysis}

All interviews were recorded with explicit permission and then transcribed. The transcriptions were supplemented by, and triangulated with, the secondary data described earlier, enabling ambiguous expressions to be clarified and amplified.

Following the procedures suggested by Corbin and Strauss [54], our analysis unfolded in two main phases. In the first phase, we began an "open coding" approach to identify concrete challenges as framed by different groups of experts. Interview transcripts were examined through a form of content analysis and expert quotes were categorized into first-order codes after the grouping of similar keywords and central meanings related to challenges. After several rounds of reexamination, we settled on a set of first-order codes that covered as much of the data as possible, representing different ways in which experts perceive the challenges of blockchain application.

In the second phase of coding, we re-grouped the first-order codes into more abstract second-order codes that summarised the concrete challenges into broader categories of challenges. We conducted an iterative examination with an objective to cover the majority of statements in the first-order codes. Eventually, seven frame content domains were generated, and theoretical saturation was achieved [55]. These domains were further compared and analyzed for similarities and differences across functions and experiences.

\section{Findings}

After conducting a deep analysis of the technological frames of three groups of experts, we adapted some of the frames proposed in Sun and Medaglia's work [56] and finally resolved seven types of perceived challenges of blockchain application in China's carbon markets: social; political, legal and policy-related; data; organizational and managerial; economic; context and technological.

Table 2 below offers a summary of perceived challenges in the adoption of blockchain technology for each group across the seven dimensions. We explore key themes that emerge from the research in relation to carbon markets in the following section.

\subsection{Social challenges}

The social challenges to the wide adoption of blockchain in carbon markets were recognized by all three groups of experts. The first perspective frequently mentioned is a paucity of understanding of blockchain's potentials in China's carbon market [2NP02, 3IT01]. This finding is consistent with our 
interviewee selection experience that experts knowing both areas remain rare.

The second perspective is that the insufficient understanding causes people to distrust blockchain. Their cognition is generally influenced by associating blockchain with cryptocurrencies, imposing a negative connotation such as illicit transactions in the deep web and Ponzi schemes related to initial coin offerings (ICO) [1PT08, 2NP03].

The third perspective focuses on difficulty in transforming from established centralization to the decentralization associated with blockchain [1PT06].

Table 2. Experts' framing of challenges in blockchain adoption in carbon markets CATEGORIES OF CHALLENGES

\begin{tabular}{|c|c|c|c|c|c|c|c|}
\hline $\begin{array}{l}\text { Key } \\
\text { players }\end{array}$ & Social & $\begin{array}{l}\text { Political, } \\
\text { legal \& } \\
\text { policy }\end{array}$ & Data & $\begin{array}{l}\text { Organizational } \\
\text { \& managerial }\end{array}$ & Economic & Context & Technological \\
\hline \multirow[t]{3}{*}{$\begin{array}{l}\text { EBP } \\
\text { - Experts } \\
\text { with } \\
\text { blockchain } \\
\text { projects }\end{array}$} & $\begin{array}{l}\text { Insufficient } \\
\text { understanding } \\
\text { from scams }\end{array}$ & $\begin{array}{l}\text { National } \\
\text { security } \\
\text { threats/data } \\
\text { leakage }\end{array}$ & $\begin{array}{l}\text { Input data } \\
\text { quality not } \\
\text { guaranteed }\end{array}$ & $\begin{array}{l}\text { Lack of a large } \\
\text { scale of } \\
\text { coordination }\end{array}$ & $\begin{array}{l}\text { High cost } \\
\text { in } \\
\text { blockchain } \\
\text { adoption }\end{array}$ & $\begin{array}{l}\text { Insufficient } \\
\text { market } \\
\text { preparation }\end{array}$ & $\begin{array}{l}\text { Limited data } \\
\text { storage on the } \\
\text { blockchain }\end{array}$ \\
\hline & $\begin{array}{l}\text { Traditional } \\
\text { thinking/model } \\
\text { of } \\
\text { centralization }\end{array}$ & $\begin{array}{l}\text { No legal or } \\
\text { regulation } \\
\text { documents }\end{array}$ & & $\begin{array}{l}\text { Lack of } \\
\text { interdisciplinary } \\
\text { talents affecting } \\
\text { government's } \\
\text { cognition }\end{array}$ & $\begin{array}{l}\text { Uncertainty } \\
\text { of profits }\end{array}$ & $\begin{array}{l}\text { Not well- } \\
\text { evolved and } \\
\text { no } \\
\text { replacement }\end{array}$ & $\begin{array}{l}\text { Low } \\
\text { transaction } \\
\text { speed }\end{array}$ \\
\hline & & $\begin{array}{l}\text { Lack of } \\
\text { supportive } \\
\text { policy } \\
\text { environment }\end{array}$ & & $\begin{array}{l}\text { No official } \\
\text { leadership }\end{array}$ & & & \\
\hline \multirow[t]{2}{*}{$\begin{array}{l}\text { EBK } \\
\text { - Experts } \\
\text { only with } \\
\text { blockchain } \\
\text { knowledge }\end{array}$} & $\begin{array}{l}\text { Willingness to } \\
\text { understand Is } \\
\text { not strong }\end{array}$ & $\begin{array}{l}\text { Lose control } \\
\text { of adjusting }\end{array}$ & $\begin{array}{l}\text { Data } \\
\text { security } \\
\text { related to } \\
\text { business } \\
\text { secrets }\end{array}$ & $\begin{array}{l}\text { Insufficient } \\
\text { motivation for } \\
\text { integration }\end{array}$ & $\begin{array}{l}\text { Uncertainty } \\
\text { of profits }\end{array}$ & & $\begin{array}{l}\text { Low } \\
\text { transaction } \\
\text { speed }\end{array}$ \\
\hline & $\begin{array}{l}\text { Insufficient } \\
\text { understanding } \\
\text { from scams }\end{array}$ & & $\begin{array}{l}\text { Input data } \\
\text { quality not } \\
\text { guaranteed }\end{array}$ & $\begin{array}{l}\text { Lack of } \\
\text { interdisciplinary } \\
\text { talents }\end{array}$ & & & $\begin{array}{l}\text { Energy } \\
\text { consumption }\end{array}$ \\
\hline \multirow[t]{2}{*}{ IT experts } & $\begin{array}{l}\text { Difficult to } \\
\text { understand } \\
\text { the technology }\end{array}$ & $\begin{array}{l}\text { Lack of } \\
\text { supportive } \\
\text { policy } \\
\text { environment }\end{array}$ & $\begin{array}{l}\text { Uncertainty } \\
\text { of data } \\
\text { ownership }\end{array}$ & $\begin{array}{l}\text { Lack of } \\
\text { interdisciplinary } \\
\text { talents }\end{array}$ & $\begin{array}{l}\text { High cost } \\
\text { in } \\
\text { blockchain } \\
\text { adoption }\end{array}$ & $\begin{array}{l}\text { Inconsistent } \\
\text { market } \\
\text { administration } \\
\text { in provinces }\end{array}$ & \\
\hline & & $\begin{array}{l}\text { Concerns } \\
\text { about future } \\
\text { legal } \\
\text { penalties }\end{array}$ & $\begin{array}{l}\text { Input data } \\
\text { quality not } \\
\text { guaranteed }\end{array}$ & $\begin{array}{l}\text { No official } \\
\text { leadership }\end{array}$ & & $\begin{array}{l}\text { Not well- } \\
\text { evolved and } \\
\text { no } \\
\text { replacement }\end{array}$ & \\
\hline
\end{tabular}

\subsection{Political, legal, and policy-related challenges}

All three expert groups mentioned these challenges, and, in particular for EBP, eight of nine experts had extensive discussions on these three perspectives.

The feature of decentralization was seen as a political threat. In China, the carbon market mechanism is regarded as a policy instrument to reduce emission of greenhouse gas and thus the market requires a high level of involvement with governmental regulation and control. Adopting blockchain in the market raises central government concerns about disempowerment and dilution of its functions in regulating and controlling carbon emissions, particularly when the smart contract enables automation in carbon market management. One expert highlighted this challenge: "theoretically, blockchain can be adopted to realize the fair allocation of [carbon emission] permits, by putting issuing rules into the smart contract and automatically issuing [carbon permit] tokens. However, it is almost impossible for the government to do this because the automation would make the government lose control of adjusting the allowance in detail. This is like issuing fiat money out of control of the central bank" [2NP01]. In addition, the immutability and transparency of data records on blockchain generate another threat to national security 
for the government. Once these data are leaked, the industrial distribution will be exposed, which threatens national economic security. As one expert emphasized: "To the government, the adoption of blockchain in the carbon market may violate their own interests making China's national energy consumption data exposed to the globe for $100 \%$. Even though there is a federal blockchain with permissioned access and transparency to all its user participants, it is highly likely that there are some spy companies exposing all energy consumption data to other countries. If one country knows our energy consumption data, they can infer what our national industrial chain is like, damaging national economic security" [1PT07].

Despite these political aspects, the regulation of blockchain adoption is largely nascent in carbon markets. There have been no official legal documents or regulation details that can guide the early practice, making it risky for the industry to embrace such technology rapidly [1PT04]. While current regulations of blockchain in the general finance industry and media opinion are strict, organizations in the carbon market are concerned about whether their efforts in early time will be in vain or, even worse, whether they will get punished as a result of some actions [1PT02].

To incentivize organizations to transfer their attention to blockchain, a positive policy environment is required to attract more practitioners. Without the government's promotion and support in either coordination or finance, organizations will have a tough time making progress in pushing the adoption to a wider range [1PT03] - in China the development of industry is always driven by government [3IT01].

\subsection{Data challenges}

Data challenges associated with blockchain adoption in carbon markets are framed as highly relevant by EBK and IT experts, but not by EBP. These data challenges include data quality, data security, and data ownership.

The first data challenge is related to data quality which consists of two levels. First, although blockchain is advantageous for immutability and traceability of data recorded on the chain, this does not mean the original data itself is authentic and accurate: "the allocation of carbon emission permits concerns report data from each company. However, if these original data were falsified before reporting to the government, then authenticity and accuracy would not be solved even when blockchain develops to version 10.0" [1PT01].

Second, the data collection method can also influence data quality. Traditional manual collection of MRV data can bring in intentional or unintentional errors, and hence blockchain still needs collaboration with some other mature technologies to maintain high data quality: "Blockchain only solves out the digital trust problem. To transform the business world to be digitalization, how to map the physical world with the digital world is key. We need advanced technologies like IoT to maintain the authenticity and reliability of original data” [1PT06].

The second challenge, framed by EBK, is data security: "Organizations are now unduly reticent on their [carbon] data because these relate to business secrets. An expert can easily estimate your company's production and scale once knowing your data. Therefore, data security is influential to organizational enthusiasm in carbon mitigation efforts" [2NP02].

The third challenge is related to the uncertainty of data ownership. Since the data on the chain are transparent to all participating nodes, each node will gain a copy of the total data. This generates a risk of drawing boundaries of data ownership: "in a federal chain, how do we take account of the data ownership, what legal structure should we draw on to identify such boundaries, and how to define the boundaries before moving on the chain" [3IT02].

\subsection{Organizational and managerial challenges}

Organizational and managerial challenges are framed by all three groups of experts. Two levels of issues were typically reported: inter-organizational management levels such as the challenge of coordination [1PT04, 2NP02], and human resource level inside an organization, in particular lack of talent in what is viewed as an interdisciplinary task in both industry [3IT01] and government [1PT03].

\subsection{Economic challenges}

Economic challenges are framed by the EBP group more frequently than the other two groups. These challenges are typical of investments in new technology and include the high cost required for application in the carbon markets [3IT03, 1PT03] and the unclear profits it brings to the business in a novel and potentially volatile market [1PT05, 2NP02].

\subsection{Context challenges}

Context challenges were emphasized only by practitioners and IT experts, and appear at two levels: at the macro level, such as insufficient market maturity; and at the micro level, such as in the lack of appropriate application scenarios.

The first challenge is related to the preparation of China's carbon market. China just started its pilot 
carbon markets from 2013 and the national carbon market from 2017. First, from a broad perspective, the current adoption of blockchain does not match the short-term and mid-term goals of China's carbon market: "the short-term goal entails the establishment of active carbon trading in the national carbon market. During this time, it is apparent that using the centralized method to build the market and start trading is better than a decentralized one. The midterm goal includes the completion of specific emission goals [...]. Using administrative measures to apportion these goals to different key emitters seem to be more effective than decentralized choices. Adopting blockchain in China's carbon market is just like using a knife to open a can" [1PT01].

Second, much fundamental work in the carbon market is still in progress, leaving a weak foundation for blockchain implementation. These include inadequate preparation of the market: regulation and standardization of carbon trading is not robust enough, falling behind other industries and inconsistent across provinces [3IT01, 3IT02].

\subsection{Technological challenges}

Technology challenges, framed only by the practitioners and non-practitioners, include the engineering nature and functional characteristics of blockchain: the low transaction speed [2NP01], limited data storage space [1PT02], and extensive energy consumption [2NP01].

\section{Discussion}

Exposing the technological frames held by three key actors has provided several insights into the progress and prospects for carbon market development and integration within China. Key to understanding the pace of development is the incongruence surfaced by this study. For example, while EBP and IT experts highlight the contextual challenges of blockchain adoption, EBK does not mention these challenges. This frame incongruence may be due to the different attitudes held by people with or without IT interaction: attitude from experts with practice is based on more evaluative beliefs of usefulness and richer perceptions [57]. Following media coverage on the hype of blockchain, experts without practice are perhaps more likely to think about the usefulness or challenges of blockchain to carbon markets, but ignore the justification of context suitability.

Another instance of frame incongruence is that while IT experts are confident in blockchain functions to date, both EBP and EBK groups are highly concerned. This paradox may be due to a knowledge background where IT experts have a stronger understanding of technological development in the short and long run.

\subsection{Implications for Practice}

5.1.1. Devising guidelines for blockchain adoption. Different expert groups have some differences in framing the challenges of blockchain adoption. While non-IT experts perceived that technological development is still needed, IT experts suggested that blockchain itself is already functionally capable of improving the efficiency of carbon markets. Assuming that both views are based on relevant expertise, this divergence indicates that policy-makers devising guidelines should survey widely to avoid vision lock-in [56].

5.1.2. Facilitating adoption with relevant processes and infrastructure. Insights from experts in China's carbon markets present a picture of the current state of blockchain adoption and help set a trajectory for technology development. Iansiti and Lakhani [3] developed a framework that maps the development strategies of blockchain in four steps based on novelty and complexity of adoption context. The present study supports their contention that understanding the context and anticipated trajectory of blockchain use can help direct organizations, industries and government to establish relevant processes and infrastructure that facilitate adoption, diffusion and hence impact.

\section{Conclusion}

This study aimed to explore the challenges of blockchain adoption in carbon markets by focusing on three key expert groups: experts with blockchain knowledge only, experts with blockchain projects, and IT experts. Using a technology frames lens, we resolved seven frames detailing the challenges those experts perceive (Section 4). Comparing these frames of challenges surfaced new insights into the current state and development trajectory of blockchain technology applied to carbon market development and integration in China. Contrasting these frames highlighted incongruence that, if ignored, may lead to vision lock-in and sub-optimal implementation.

It should be remembered that this work is exploratory and although it confirms general observations about technology implementation and adoption, we recognize the limited generalisability of our research findings due to a narrow domain focus, a narrow regional focus, and the low number and diversity of respondents reached at saturation [52] [58]. 
However, this work identifies and starts to address a number of research gaps: extending the current discussion on blockchain from technical aspects to socio-technical aspects and hence moving to more rigorous empirical and theory-driven research on blockchain within the IS discipline that sets the technical challenges in a much wider context and sets the foundation for a non-deterministic approach to research adoption and diffusion of blockchain technology.

\section{Acknowledgements}

We gratefully acknowledge the contribution of the experts interviewed, the organisations cited, and guidance from the HICSS panel and colleagues, particularly Professor Malcolm Atkinson (Edinburgh).

\section{References}

[1] A. S. Nakamoto, "Bitcoin: A Peer-to-Peer Electronic Cash System”, 2008.

[2] I. Bashir, Mastering blockchain, Packt Publishing, 2017.

[3] M. Iansiti and K. R. Lakhani, "The Truth About Blockchain”, Harv Bus Rev, 95(1), 2017, pp. 118-127.

[4] T. Aste, P. Tasca, and T. Di Matteo, "Blockchain Technologies: foreseeable impact on industry and society", Computer, 50, 2017, pp. 18-28.

[5] R. Beck and C. Müller-Bloch, "Blockchain as Radical Innovation: A Framework for Engaging with Distributed Ledgers", in 50th Hawaii Int. Conf. System Sciences. Waikoloa, 2017.

[6] A. Y. L. Chong, E. T. Lim, X. Hua, S. Zheng, and C. W. Tan, "Business on Chain: A Comparative Case Study of Five Blockchain-Inspired Business Models", JAIS, 20(9), 2019, 1308-1337.

[7] Y. Wang, M. Singgih, J. Wang, and M. Rit, "Making sense of blockchain technology: How will it transform supply chains?", Int J Prod Econ., Elsevier, 211, 2019, pp. 221-236.

[8] V. Buterin, Ethereum [Online]. https://github.com/ethereum/wiki/wiki/White-Paper, 2013.

[9] Kamble, S., Gunasekaran, A. and Arha, H., 2019. Understanding the Blockchain technology adoption in supply chains-Indian context. Int. J. Prod. Res., 57(7), pp.2009-2033.

[10] Kouhizadeh, M., Saberi, S. and Sarkis, J., 2020. Blockchain technology and the sustainable supply chain: Theoretically exploring adoption barriers. Int J Prod Econ., 231, p.107831.

[11] S. Miau, and J. M. Yang, "Bibliometrics-based evaluation of the Blockchain research trend: 2008 March 2017", Technol Anal Strateg Manag. Taylor \& Francis, 0(0), 2018, pp. 1-17.

[12] M. Dabbagh, M. Sookhak, and N. S. Safa, "The evolution of blockchain: A bibliometric study", IEEE Access. IEEE Inc., 7, 2019, pp. 19212-19221.
[13] F. Glaser, and L. Bezzenberger, "Beyond cryptocurrencies-a taxonomy of decentralized consensus systems", in 23rd European Conf. Inf Syst., 2015.

[14] M. Morisse, "Cryptocurrencies and Bitcoin: Charting the Research Landscape", in 21st Americas Conf. Inf Syst., Puerto Rico, 2015.

[15] F. Tschorsch, and B. Scheuermann, B. "Bitcoin and Beyond: A Technical Survey on Decentralized Digital Currencies", IEEE Commun. Surv. Tutor., 18(3), 2016, pp. 2084-2123.

[16] J. Yli-Huumo, D. Ko, S. Choi, S. Park, and K. Smolander "Where Is Current Research on Blockchain Technology? - A Systematic Review", PLOS ONE, 10(11), 2016.

[17] M. Risius and K. Spohrer, "A Blockchain Research Framework: What We (don't) Know, Where We Go from Here, and How We Will Get There", Bus. Inf. Syst. Eng.. Springer Fachmedien Wiesbaden, 59(6), 2017, pp. 385-409.

[18] R. Beck, M. Avital, M. Rossi, and J. B. Thatcher, "Blockchain Technology in Business and Information Systems Research", Bus. Inf. Syst. Eng.. Springer Fachmedien Wiesbaden, 59(6), 2017, pp. 381-384.

[19] J. Lindman, M. Rossi, and V. K. Tuunainen,. "Opportunities and risks of Blockchain Technologies in payments- a research agenda", HICSS 2017 Proceedings, 2017, pp. 1533-1542.

[20] J. Macinante, "Networking Carbon Markets-Key Elements of the Process", (July). Available at: http://pubdocs.worldbank.org/en/974651467928322884/ Networking-Carbon-Markets-Macinante-2016-dft-2230616-jdm-clean-copy.pdf 2016.

[21] T. Baumann, Blockchain For Planetary Stewardship: Using the Disruptive Force of Distributed Ledger Technology to Fight Climate Disruption. CA, USA, 2018.

[22] X. Dong, R.C.K. Mok, D. Tabassum, P. Guigon, E. Ferreira, C.S. Sinha, N. Prasad, J. Madden, T. Baumann, J. Libersky, E. McCormick, J. Cohen, Blockchain and Emerging Digital Technologies for Enhancing Post2020 Climate Markets. Washington, DC, 2018.

[23] A. Jackson, L. Ashley, M. Justin, and H. Markus, "Networked Carbon Markets: Permissionless Innovation with Distributed Ledgers?", SSRN, 2017, pp. 1-15.

[24] D. B. Chen, "Utility of the blockchain for climate mitigation", The Journal of The British Blockchain Association, 1(1), 2018.

[25] S. Hartmann and S. Thomas, "Applying Blockchain to the Australian Carbon Market", Economic Papers, (113), 2019, pp. 1-19.

[26] K. Francisco, and S. David, "The Supply Chain Has No Clothes: Technology Adoption of Blockchain for Supply Chain Transparency", Logistics. Multidisciplinary Digital Publishing Institute, 2(1), 2018, 2.

[27] L. Schneider, A. Kollmuss, and M. Lazarus, "Addressing the risk of double counting emission reductions under the UNFCCC", Clim Change. Springer, 131(4), 2015, pp. 473-486.

[28] K. N. Khaqqi, J. S. Janusz, H. Kunn, and K.Markus, "Incorporating seller/buyer reputation-based system in 
blockchain-enabled emission trading application", Appl. Energy. Elsevier Ltd, 209, 2018, pp. 8-19.

[29] E. Narassimhan, E. S. G. Kelly, K. Stefan, and R. A. Julio, "Climate Policy Carbon pricing in practice: a review of existing emissions trading systems", Clim. Policy, 18(8), 2018, pp. 967-991.

[30] C. Catalini, "How blockchain technology will impact the digital economy the platform of the future?",

Blockchains Smart Contracts Internet Things, 4, 2017, pp. 2292-2303.

[31] M. Swan, Blockchain : blueprint for a new economy. O'Reilly Media, Inc, 2015.

[32] M. Andoni, R. Valentin, F. David, A. Simone, G. Dale, J. David, M. Peter, and P. Andrew, "Blockchain technology in the energy sector: A systematic review of challenges and opportunities", Renew. Sust. Energ. Rev. . Elsevier Ltd, 2019, pp. 143-174.

[33] C. Flachsland, R. Marschinski, and O. Edenhofer, "To link or not to link: benefits and disadvantages of linking cap-and-trade systems", Climate Policy, 9(4), 2009, pp. 358-372.

[34] M. A. Mehling, G. E. Metcalf, and R. N. Stavins, "Linking climate policies to advance global mitigation", Science, 359(6379), 2018, pp. 997-998.

[35] S. R. Goers, B. Pflüglmayer, and M. J. Luger, "Design Issues for Linking Emissions Trading Schemes-A Qualitative Analysis for Schemes from Europe, Asia and North America", J. Environ. Health Sci. Eng. B1, 1, 2012, pp. 1322-1334.

[36] C. M. Black, "Taxation of Cross-Border Transfers of Carbon Emission Allowances under Linked Emissions Trading Schemes", Transnatl. Environ. Law, 6(2), 2020, pp. 335-361.

[37] J. Jaffe, and R. Stavins, Linkage of Tradable Permit Systems in International Climate Policy Architecture. 14432. Cambridge, MA, 2008.

[38] M. Ranson, and R. N. Stavins, "Linkage of greenhouse gas emissions trading systems: learning from experience", Clim. Policy, 16(3), 2016, pp. 284-300.

[39] J. D. Macinante, A Conceptual Model for Networking of Carbon Markets on Distributed Ledger Technology Architecture, 2017.

[40] M. Russinovich, E. Ashton, C. Avanessians, M. Castro, A. Chamayou, S. Clebsch, M. Costa, C. Fournet, M. Kerner, S. Krishna, and J. Maffre, "CCF: A Framework for Building Confidential Verifiable Replicated Services", Technical Report MSR-TR-2019-16, Microsoft, 2019.

[41] M. Fishbein and I. Ajzen, Belief, Attitude, Intention, and Behavior, Reading, MA: Addison-Wesley, 1975.

[42] F.D. Davis, P. Bagozzi and P.R. Warshaw, "User Acceptance of Computer Technology: A comparison of two models", Manage Sci, 35(8), 1989, pp.982-1001.

[43] I. Ajzen, I. "The Theory of Planned Behavior", Organ Behav Hum Decis Processses, 50(2), 1991, pp. 179211.
[44] V. Venkatesh, M.G Morris, G.B. Davis and F.D. Davis, "User Acceptance of Information Technology: Toward an unified view", MIS Q, 27(3), 2003, pp. 425-478.

[45] W. J. Orlikowski and D. C. Gash,"Technological Frames: Making Sense of Information Technology in Organizations", ACM Trans Inf Syst. (TOIS), 12(2), 1994, pp. 174-207.

[46] E. J. Davidson, "Technology Frames and Framing: A Socio-Cognitive Investigation of Requirements", MIS Q, 26(4), 2002, pp. 329-358.

[47] S. Kaplan, and M. Tripsas, "Thinking about technology: Applying a cognitive lens to technical change", Res Policy. 37(5), 2008, pp. 790-805.

[48] J. P. Cornelissen and M. D. Werner, "Putting Framing in Perspective: A Review of Framing and Frame Analysis across the Management and Organizational Literature", Acad Manag Ann. 8(1), 2014, pp. 181-235.

[49] Ministry of Ecology and Environment of the P.R.C., Mandates of Ministry of Ecology and Environment of People's Republic of China. Available at: http://english.mee.gov.cn/About_MEE/Mandates/, 2018

[50] Certification and Accreditation Administration of the P.R.C., Main Responsibilities of Certification and Accreditation Administration. Available: http://english.cnca.gov.cn/about/201512/t20151223_423 80.shtml 2015.

[51] G. Guest, A. Bunce, and L. Johnson, "How Many Interviews Are Enough? An Experiment with Data Saturation and Variability", Field Methods, 18(1), 2016, pp. 59-82.

[52] JJ. Francis, M. Johnston, C. Robertson, L. Glidewell, V. Entwistle, M. P. Eccles, and J. M. Grimshaw,"What is an adequate sample size? Operationalising data saturation for theory-based interview studies", Psychol Health. 25(10), 2020, pp. 1229-1245.

[53] M. D. Myers and M. Newman, "The qualitative interview in IS research: Examining the craft", Inf. Organ. Pergamon, 17(1), 2007, pp. 2-26.

[54] J.M. Corbin and A. Strauss, Basics of qualitative research: Techniques and procedures for developing grounded theory. Los Angeles: Sage, 2008.

[55] K. M. Eisenhardt, "Building Theories from Case Study Research", Acad Manage Rev, 14(4), 1989, pp. 532550.

[56] T. Q. Sun and R. Medaglia, "Mapping the challenges of Artificial Intelligence in the public sector: Evidence from public healthcare", Gov Inf Q. JAI, 36(2), 2019, pp. 368-383.

[57] E. Karahanna, D. W. Straub, and N. L. Chervany, "Information Technology Adoption Across Time: A Cross-Sectional Comparison of Pre-Adoption and PostAdoption Beliefs", MIS Q, 23(2), 1999, pp. 183-213.

[58] B. G. Glaser and A. L. Strauss, The discovery of grounded theory: Strategies for qualitative research, New York: Aldine Pub, 1967. 